\title{
Mitigative Effects of Coconut Oil and Its Water on the Lungs of Male Albino Rats Exposed to Petrol Vapour
}

\author{
Onifade $\mathrm{OF}^{* 1}$, Ayodele $\mathrm{PF}^{* 2}$, Ololade $\mathrm{ZS}^{3}$ and Balogun $\mathrm{DO}^{4}$ \\ ${ }^{1,4}$ Department of Chemical and Food Sciences, College of Natural and Applied Sciences, Bells University, Ota, Ogun State, Nigeria
} ${ }^{2}$ Department of Biochemistry, College of Biosciences, Federal University of Agriculture, Abeokuta, Ogun State, Nigeria

${ }^{3}$ Department of Chemistry, Faculty of Sciences, University of Medical Sciences, Ondo State, Nigeria

*Both authors contributed equally

*Corresponding author: Onifade OF, Department of Chemical and Food Sciences, College of Natural and Applied Sciences, Bells

University, Ota, Ogun State, Nigeria

\section{ARTICLE INFO}

Received: 豐 January 20, 2020

Published: 慧 January 30, 2020

Citation: Onifade OF, Ayodele PF, Ololade ZS, Balogun DO. Mitigative Effects of Coconut Oil and Its Water on the Lungs of Male Albino Rats Exposed to Petrol Vapour. Biomed J Sci \& Tech Res 25(1)-2020. BJSTR. MS.ID.004155.

Abbreviations: PMS: Petrol or Premium Motor Spirit; GSH: Glutathione; MDA: Malondialdehyde; H\&E: Hematoxylin and Eosin; SOD: Superoxide Dismutase; CAT: Catalase; GSH: Gluthathione; SEM: Standard Error of Mean; ANOVA: Analysis of Variance; TAG: Triacylglycerol; HDL: High Density Lipoprotein; LDL: Low Density Lipoprotein; Chol: Cholesterol; ROS: Reactive Oxygen Species

\section{ABSTRACT}

This study examined the effects of Petrol or Premium Motor Spirit (PMS) vapour on lungs and the impact of coconut oil and coconut water in ameliorating its degenerative effects. Thirty-five albino rats were grouped into seven groups $(n=5)$. Groups $1,2,3,4,5$, and 7 were exposed to PMS vapour using an inhalation chamber, 8 hours daily for two weeks. Groups 1 and 2 were treated with $0.4 \mathrm{ml} / \mathrm{kgb} . \mathrm{w}$ coconut oil and coconut water respectively; group 3 was treated with a regular drug (indapamine) at $0.4 \mathrm{ml} / \mathrm{kgb} . \mathrm{w}$; and groups 4 and 5 were treated with $0.2 \mathrm{ml} / \mathrm{kgb.w}$ coconut oil and coconut water respectively. Group 6 was negative control and were neither exposed nor treated while group 7 was positive control, exposed to petrol vapour but not treated. Histological analysis showed that the lungs of the experimental test groups indicated degenerative changes in the ultrastructural integrity of interstitium cells. The lungs showed a significant decrease $(p<0.05)$ in the glutathione $(\mathrm{GSH})$ level on exposure for two weeks when compared with the negative control. It was also observed that the level of malondialdehyde (MDA) increased significantly in all exposed groups compared with the negative control. Treatment with coconut water significantly $(\mathrm{p}<0.05)$ reduced the effects of PMS vapor on the levels of GSH and MDA when compared with the other groups. Hence, treatment with coconut water and oil may provide a useful preventive measure against tissue injury consequent to exposure to PMS vapour experienced in our houses and at petrol filling stations.

Keywords: Pollution; Premium Motor Spirit; Volatile Hydrocarbons; Human Activities; Inhalation

\section{Introduction}

Environmental pollution occurs as a result of human activities and natural forces such as consumption of solid fuels for cooking, heating, cigarette smoking, incinerators, waste disposals, increasing industrialization, motor vehicles, natural disasters, forest and agricultural fires [1]. Petrol also known as Premium Motor Spirit (PMS) is distilled from crude petroleum, and vapour obtained from its evaporation may be considered as petrol fumes. The PMS is used as fuel for internal combustion engines, decorative agent, and industrial solvent. Some of its constituents are known to be highly toxic or carcinogenic to humans [2]. The PMS contains a mixture of volatile hydrocarbons and this makes it readily available in the atmosphere anytime it is dispensed [3]. Inhalation is the most common form of exposure. The applications of fuel as cooking and lighting fuels in the home have resulted in direct exposure of these products to a good percentage of the populace. However, the most affected are those who occupationally are always exposed to the fumes [4]. Coconut is a drupe that contains constituents that act as antioxidants, anti-inflammatory, anti-viral, anti-bacterial, anti-fungal anti-microbial [5]. Although exposure to PMS is common, the mitigating effect of coconut oil and its water as a substitute for modern day treatment of the effects of PMS inhalation is limited. This research therefore aims to find out the 
mitigating effects that coconut oil and its water have on the damage caused d by PMS inhalation.

\section{Materials and Methods}

\section{Procurement and Preservation of Coconut Water}

The coconuts were bought from Oja market in Ota, Ogun state and the coconut water were obtained freshly from three coconuts daily.

\section{Extraction of Coconut Oil}

Cold extraction method was used for extracting coconut oil from the coconut milk by breaking the emulsion without heating The edibles part of coconut obtained from a fully developed brown coconut were cut into tiny pieces and blended with a blender. The blended coconut was filtered using cheesecloth into a clean bucket to remove the milk. The milk was left for two days to separate, leaving the oil to rise to the top and the coconut milk to settle at the bottom of the jar. The coconut oil was scooped into plain sample bottles and stored in a dark place away from sunlight.

\section{Experimental Animals}

Thirty-five male albino rats were purchased from a farmhouse in Lagos University Teaching Hospital. They were housed in plastic cages with net covers for ventilation and subjected to a standard environmental condition (12:12 hour light: dark cycle). The rats were fed ad-libitum. Wood shavings were used as beddings for the animals. The beddings were changed daily to avoid buildup of toxic ammonia levels. The rats were allowed two weeks acclimatization period prior to exposure. The care of the experimental animals was in accordance to all the necessary rules and regulations in animal research.

\section{Animal Grouping and Exposure}

The rats were divided into seven (7) groups, including the positive and negative control group. Each group contained five (5) animals to avoid overcrowding and to allow easy accessibility and identification of the animals in the course of the research. Using an inhalation chamber, all the groups, excluding the negative control group were introduced to PMS by inhalation respectively and proper precautions were taken 8 hours daily for two weeks after which treatment was administered for one week. The weight of each rat was taken before and after treatment. Using a measuring cylinder, 500ml of PMS was measured and distributed among five (5) perforated cans and placed in front of each cage. At the end of daily exposure, the final volume of the petrol was recorded.

\section{Biochemical Analysis}

At the end of the experiment, the albino rats were sacrificed by cervical dislocation. The lungs were harvested. Histological preparations were made from these tissues for histological analysis. The lungs of the rats in each group were used to carry out analysis on oxidative stress and blood samples were taken for lipid profile.

\section{Histopathology Procedure}

Histopathology is the microscopic study of diseased tissue. It is performed by examining a thin tissue section under light microscopes. The tissues were fixed with neutral formalin 10 $\%$, embedded in paraffin, and then manually sectioned with a microtome to obtain $4-5 \mu \mathrm{m}$ thick paraffin sections. Dewaxed sections were then stained with hematoxylin and eosin (H\&E) dyes. After staining, a very thin glass was placed over the tissue sections to protect them and to enhance the optical evaluation of the tissues.

\section{Method for Homogenizing Sample}

Harvested organs of the animal were prepared by washing them in ice cold $1.15 \% \mathrm{KCl}$ solution, blotted and weighed. They were then homogenized with $0.1 \mathrm{M}$ phosphate buffer $(\mathrm{pH} 7.2)$, putting the organs each into the homogenizing cup and homogenized using the homogenizer. The resulting homogenate was centrifuge at 2500 rpm for 15 mins. Supernatant was obtained and stored at $-20^{\circ} \mathrm{C}$ until analysis.

\section{Lipid Profiles Assay}

Determination of Triacylglycerol (TAG) Concentration: Triacylglycerol is the main storage form of fatty acids. Triacylglycerol measurement is used in diagnosis and treatment of diseases involving lipid metabolism.

Procedure: Three test tubes marked blank (B), test (T) and standard (S) was arranged in a test tube rack. To each of the test tubes was pipetted $1.0 \mathrm{ml}$ of the monoreagent (PIPES buffer $50 \mathrm{mmol} / \mathrm{L} \mathrm{pH}$ 6.8, LPL $12 \mathrm{KU} / \mathrm{L}$, GK $1 \mathrm{KU} / \mathrm{L}$, GPO 10KU/L, ATP $2.0 \mathrm{mmol} / \mathrm{l}, \mathrm{Mg}^{2+} 40 \mathrm{mmol} / \mathrm{l}$, POD 2.5KU/L, 4-amino antipyrine $(0.5 \mathrm{mmol} / \mathrm{L})$, phenol $(3 \mathrm{mmol} / \mathrm{L})$. Then, $10 \mu \mathrm{L}$ of serum and $10 \mu \mathrm{L}$ of calibrator (triacylglycerol standard; glycerol $12.26 \mathrm{mmol}$, equivalent to $200 \mathrm{mg} / \mathrm{dl}$ of glycerol trioleate) were pipetted into tube marked $\mathrm{T}$ and $\mathrm{S}$ respectively. The reaction mixture was thoroughly mixed and incubated for 15 mins at $25^{\circ} \mathrm{C}$. The absorbance of the samples and standard was read at $505 \mathrm{~nm}$ against the reagent blank.

Triacylglycerol concentration $(\mathrm{mg} / \mathrm{dl})$ in the serum was calculated as:

$$
\text { Triacylglycerol }=\frac{\text { Absorbance of sample }}{\text { Absorbance of standard }} \times 200
$$

Where: $200 \mathrm{mg} / \mathrm{dL}$ is the concentration of standard.

Determination of Cholesterol (Chol) Concentration: Cholesterol is produced in the body, in quantities needed for the body to function properly. Sources of some cholesterol is diet, hence comsuming food high in saturated fat and trans-fat resulted in high level of cholesterol in the blood. Cholsterol measment is used in the diagnosis and treatment of of lipoprotein metabolism disorder.

Procedure: Three test tubes marked blank (B), test (T) and standard (S) were arranged in a test tube rack. To each of the test tube was added $1 \mathrm{ml}$ of monoreagent (PIPES $200 \mathrm{mmol} / \mathrm{l}, \mathrm{pH} 7.0$, sodium cholate $1 \mathrm{mmol} / \mathrm{l}$, cholesterol esterase $250 \mathrm{U} / \mathrm{L}$, cholesterol 
oxidase $250 \mathrm{U} / \mathrm{L}$, ADPS $0.4 \mathrm{mmol}$ ). Then $10 \mu \mathrm{L}$ of standard cholesterol solution and $10 \mu \mathrm{L}$ of plasma were pipetted into tubes labeled $\mathrm{S}$ and $\mathrm{T}$ respectively. Cholesterol concentration was calculated as:

$$
\text { Cholesterol }=\frac{\text { Absorbance of sample }}{\text { Absorbance of standard }} \times 200 \mathrm{mg} / \mathrm{dl}
$$

Where: $200 \mathrm{mg} / \mathrm{dl}$ is the concentration of the standard.

Determination of High-Density Lipoprotein (HDL) Concentration: High density lipoprotein fraction was first isolated according to the method of [6] after precipitating very low-density lipoprotein (VLDL) and low-density lipoprotein (LDL).

Determination of Low-Density Lipoprotein (LDL) Concentration: Low density concentration was determined using $\mathrm{LDL}=$ Cholesterol $-\{(\mathrm{TAG} / 2.22)+\mathrm{HDL}\}$

\section{Antioxidant Enzymes Assay}

Determination of Superoxide Dismutase (SOD) Activity: Superoxide dismutase activity was determined by its ability to inhibit the auto-oxidation of epinephrine determined by the increase in absorbance at $480 \mathrm{~nm}$ as described by [7]. The reaction mixture $(3 \mathrm{ml})$ contained $2.95 \mathrm{ml}$ of $0.05 \mathrm{M}$ sodium carbonate buffer pH $10.2,0.02 \mathrm{ml}$ of liver homogenate and $0.03 \mathrm{ml}$ of epinephrine in $0.005 \mathrm{~N} \mathrm{HCl}$ was used to initiate the reaction. The reference cuvette contained $2.95 \mathrm{ml}$ buffer, $0.03 \mathrm{ml}$ of substrate (epinephrine) and $0.02 \mathrm{ml}$ of water. Enzyme activity was calculated by measuring the change in absorbance at $480 \mathrm{~nm}$ for $5 \mathrm{~min} . \sum=4020 \mathrm{M}^{-1} \mathrm{~cm}^{-1}$.

Determination of Catalase (CAT) Activity: Catalase (CAT) activity was determined according to Sinha [8]. It was assayed colorimetrically at $620 \mathrm{~nm}$ and expressed as $\mu$ moles of $\mathrm{H}_{2} \mathrm{O}_{2}$ consumed per min/mg protein at $250{ }^{\circ} \mathrm{C}$. The reaction mixture (1.5ml) contained $1.0 \mathrm{ml}$ of $0.01 \mathrm{M}$ phosphate buffer $(\mathrm{pH} 7.0), 0.1 \mathrm{ml}$ of tissue homogenate and $0.4 \mathrm{ml}$ of $2 \mathrm{M} \mathrm{H}_{2} \mathrm{O}_{2}$. The reaction was stopped by the addition of $2.0 \mathrm{ml}$ of dichromate-acetic acid reagent (5\% potassium dichromate and glacial acetic acid were mixed in $1: 3$ ratio). $\sum=40 \mathrm{M}^{-1} \mathrm{~cm}^{-1}$.

Determination of Reduced Gluthathione (GSH) Level: The reduced glutathione (GSH) content of liver tissue as non-protein sulphydryl was estimated according to the method described by [9]. To the homogenate $10 \%$ TCA was added, centrifuged. $1.0 \mathrm{ml}$ of supernatant was treated with $0.5 \mathrm{ml}$ of Ellmans reagent $119.8 \mathrm{mg}$ of 5, 5-dithiobisnitro benzoic acid (DTNB) in $100 \mathrm{ml}$ of $0.1 \%$ sodium nitrate) and $3.0 \mathrm{ml}$ of phosphate buffer $(0.2 \mathrm{M}, \mathrm{pH} 8.0)$. The absorbance was read at $412 \mathrm{~nm} . \sum=1.34 \times 10^{4} \mathrm{M}^{-1} \mathrm{~cm}^{-1}$.
Determination of Lipid Peroxidation: Malondialdehyde (MDA) an index of lipid peroxidation was determined using the method of [10].1.0 $\mathrm{ml}$ of the supernatant was added to $2 \mathrm{ml}$ of (1:1:1 ratio) TCA-TBA-HCl reagent (Thiobarbituric acid $0.37 \%$, $0.24 \mathrm{~N} \mathrm{HCl}$ and $15 \%$ TCA) Tricarboxylic acid- thiobarbituric acidhydrochloric acid reagent boiled at $100{ }^{\circ} \mathrm{C}$ for $15 \mathrm{~min}$, and allowed to cool. Flocculent materials were removed by centrifuging at 3000 rpm for $10 \mathrm{~min}$. The supernatant was removed, and the absorbance read at 532nm against a blank. MDA was calculated using the molar extinction coefficient for MDATBA- complex of $1.56 \times 10^{5} \mathrm{M}^{-1} \mathrm{~cm}^{-1}$.

$$
M D A(\text { unit } / m g / \text { protein })=\frac{\text { absorbance }}{\text { Molar extinction } \times m g \text { protein }}
$$

\section{Statistical Analysis}

Data were expressed as mean \pm standard error of mean (SEM) and were analyzed with software package for social science (SPSS) version 17 and one-way analysis of variance (ANOVA) for multiple comparisons between groups, followed by the Newman-Keuls Post Hoc Test. Difference between groups were considered significant at $\mathrm{p}<0.05$.

\section{Results}

\section{Histology}

Histopathology of the lungs of the experimental rats.

\section{Discussion}

The toxicity of PMS vapour as well as the mitigating effect of coconut oil and coconut water on the levels of serum lipid profile (triglyceride, cholesterol, high density lipoprotein, and low density lipoprotein), lipid peroxidation level (MDA), antioxidant enzymes (reduced glutathione, catalase, and superoxide dismutase) and histological examination in the lungs of the experimental rats are shown above. The level of triacylglycerol (TAG) of the animals is presented in Figure 1. There is an elevation in TAG level, with groups 1,3 and 4 showing a significant $(p<0.05)$ increase compared to group 6 and group 7. The level of cholesterol (Chol) of the animals is presented in Figure 2. There is a significant $(p<0.05)$ difference in cholesterol level, with groups 1 and 5 showing a significant $(\mathrm{p}<$ $0.05)$ decrease compared to group 7 and a significant $(\mathrm{p}<0.05)$ increase compared to group 3. Group 2 has a significant $(\mathrm{p}<0.05)$ increase compared to groups 6 and group 7. The level of highdensity lipoprotein (HDL) in the serum of the animals is presented in Figure 3. There is a significant $(p<0.05)$ difference in HDL level, with group 2 showing a significant $(\mathrm{p}<0.05)$ increase compared to groups 6 and group 7.

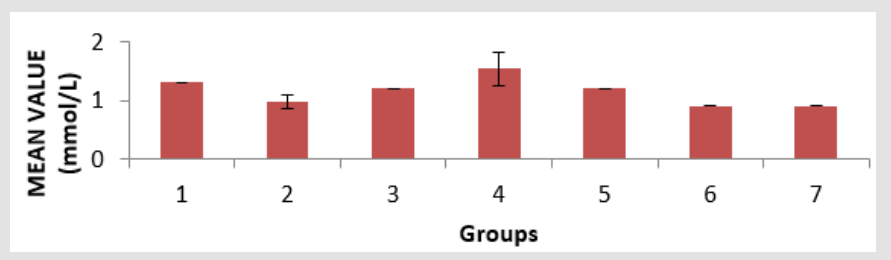

Figure 1: Triacylglycerol (TAG) level in the serum of the experimental animals. Values were expressed as mean of three determinations \pm SEM. Differences were considered significant at $\mathrm{p}<0.05$. 


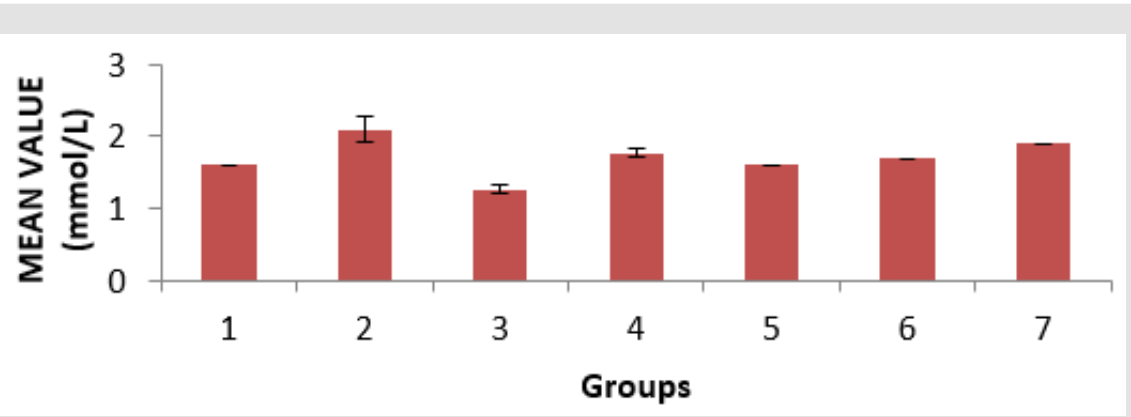

Figure 2: Cholesterol (Chol) level in the serum of the experimental animals. Values were expressed as mean of three determinations \pm SEM. Differences were considered significant at $p<0.05$.

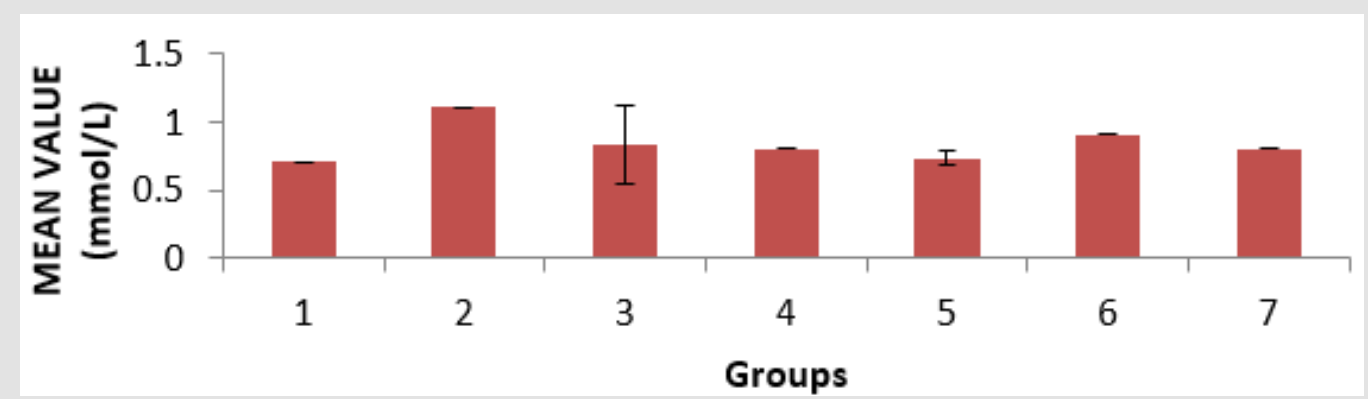

Figure 3: High density lipoprotein (HDL) level in the serum of the experimental animals. Values were expressed as mean of three determinations \pm SEM. Differences were considered significant at $p<0.05$.

The level of low-density lipoprotein (LDL) in the serum of the animals is presented in Figure 4. Group 4 showed a significant ( $\mathrm{p}$ $<0.05$ ) decrease compared to groups 6 and group 7, and group 6 showed a significant $(\mathrm{p}<0.05)$ decrease compared to groups 2 and group 4. The level of Malondialdehyde (MDA) in the lungs of the animals is presented in Figure 5. There is a significant $(\mathrm{p}<0.05)$ difference in MDA level, with group 3 showing a significant ( $p<$ 0.05 ) increase compared to group 6 only. The reduced glutathione (GSH) level of the animals is presented in Figure 6. There is a significant $(p<0.05)$ decrease in the GSH level. Group 1, 2 and 4 showed a significant $(\mathrm{p}<0.05)$ decrease compared to groups 6 and 7. The catalase (CAT) activity of the animals is presented in Figure
7. There is a significant $(\mathrm{p}<0.05)$ decrease in group 1 compared to group 6. Group 2 showed a significant $(p<0.05)$ increase compared to groups 3 and 4 . Group 5 showed a significant $(p<0.05)$ increase compared to group 7. The superoxide dismutase (SOD) activity of the animals is presented in Figure 8. Group 1 sowed a significant $(\mathrm{p}<0.05)$ decrease in SOD activity compared to group 3. Group 2 showed a significant $(p<0.05)$ decrease compared to group 3. Group 4 showed a significant $(p<0.05)$ increase compared to groups 6 and group 7. Group 5 showed a significant increase $(p<$ 0.05 ) compared to groups 6 and 7. Plate 1 showed the toxic effect of PMS vapour and the mitigating effect of coconut oil and its water on damaged lungs of the animals.

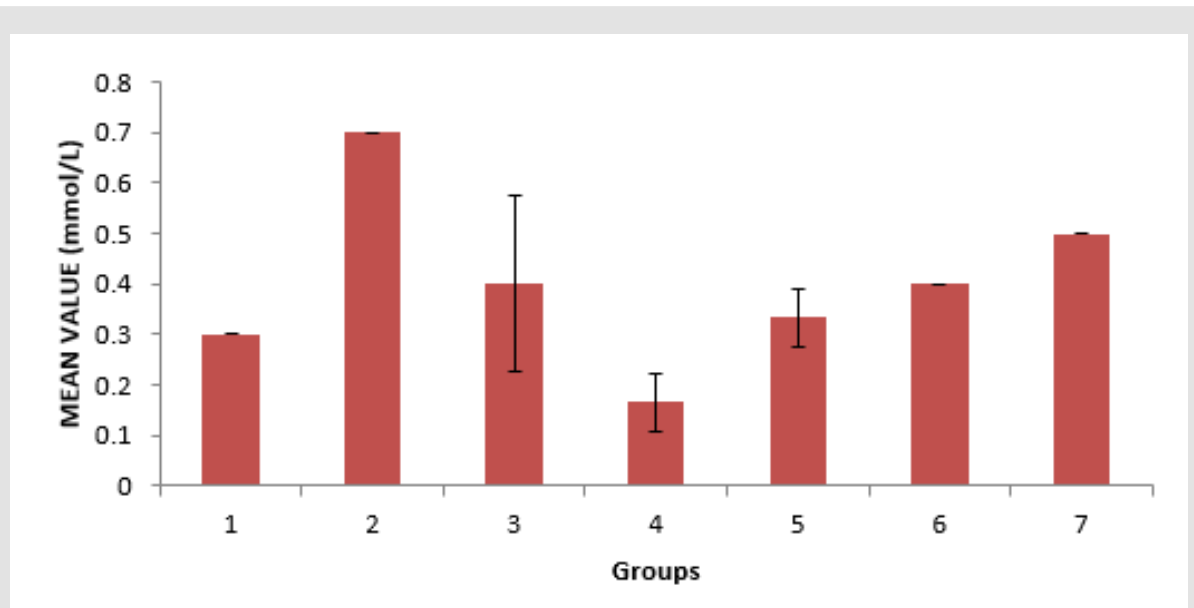

Figure 4: Low density lipoprotein (LDL) level in the serum of the experimental animals. Values were expressed as mean of three determinations \pm SEM. Differences were considered significant at $\mathrm{p}<0.05$. 


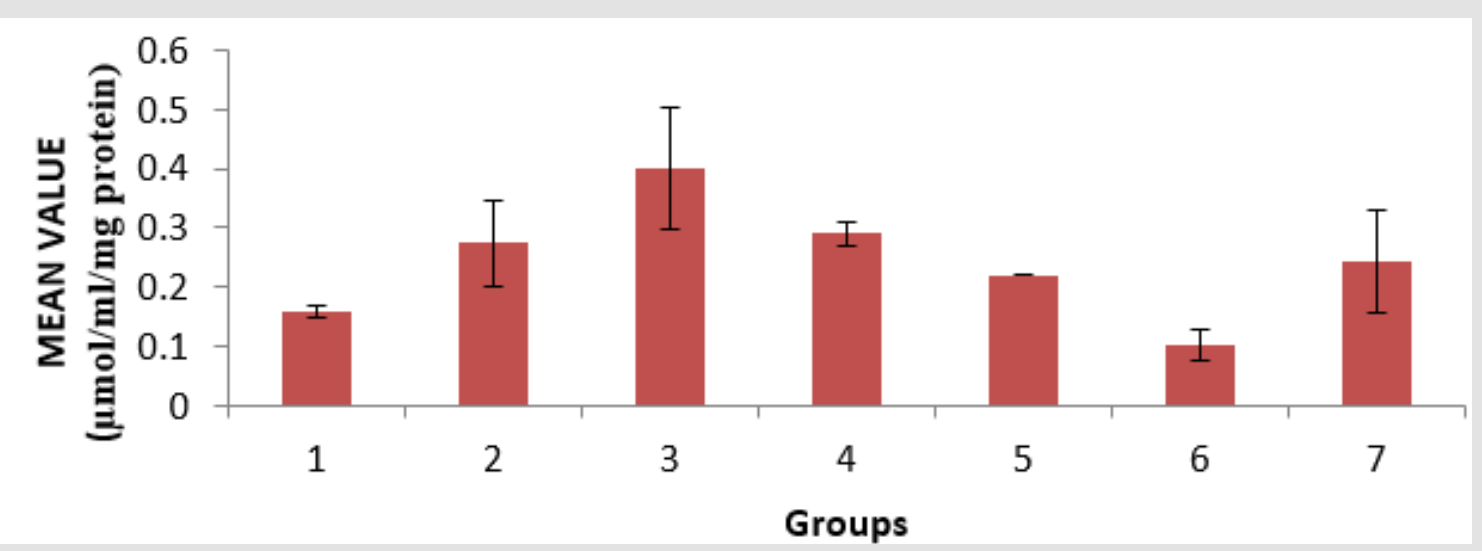

Figure 5: Malondialdehyde (MDA) level in the lungs of the experimental animals. Values were expressed as mean of three determinations \pm SEM. Differences were considered significant at $p<0.05$.

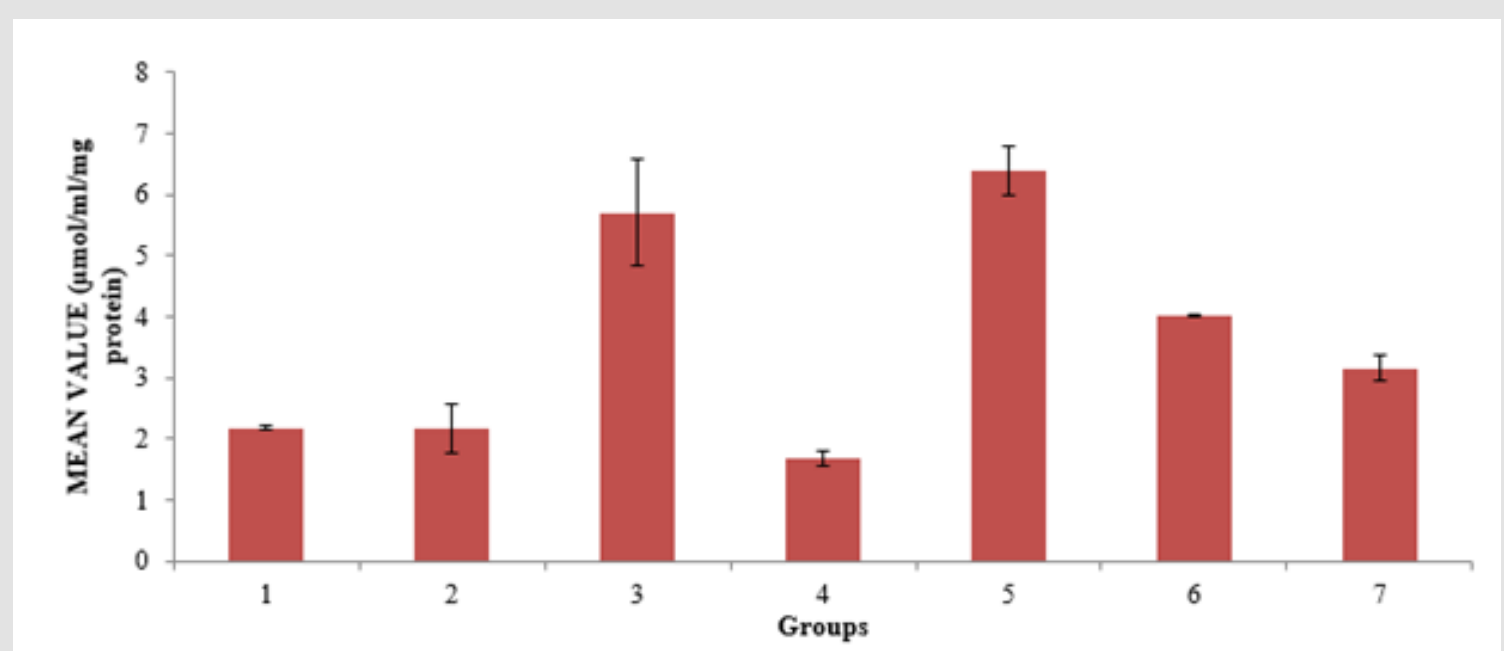

Figure 6: Reduce glutathione (GSH) level in the lungs of the experimental animals. Values were expressed as mean of three determinations \pm SEM. Differences were considered significant at $p<0.05$.

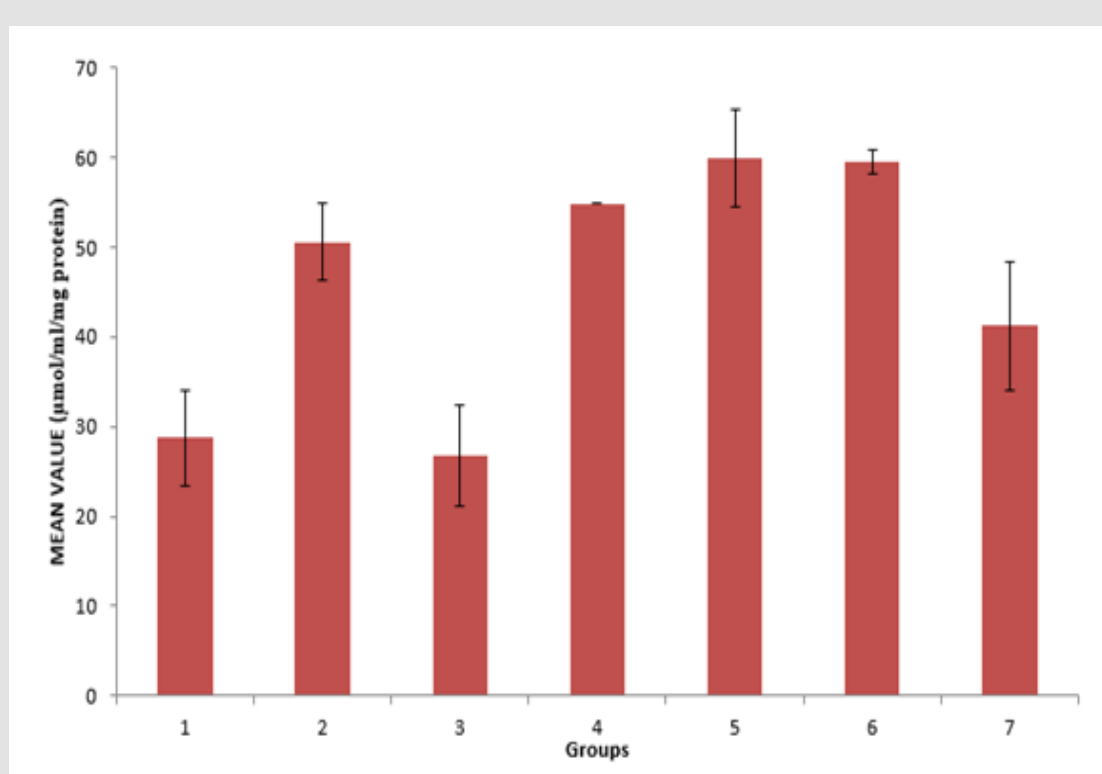

Figure 7: Catalase (CAT) activity in the lungs of the experimental animals. Values were expressed as mean of three determinations \pm SEM. Differences were considered significant at $\mathrm{p}<0.05$. 


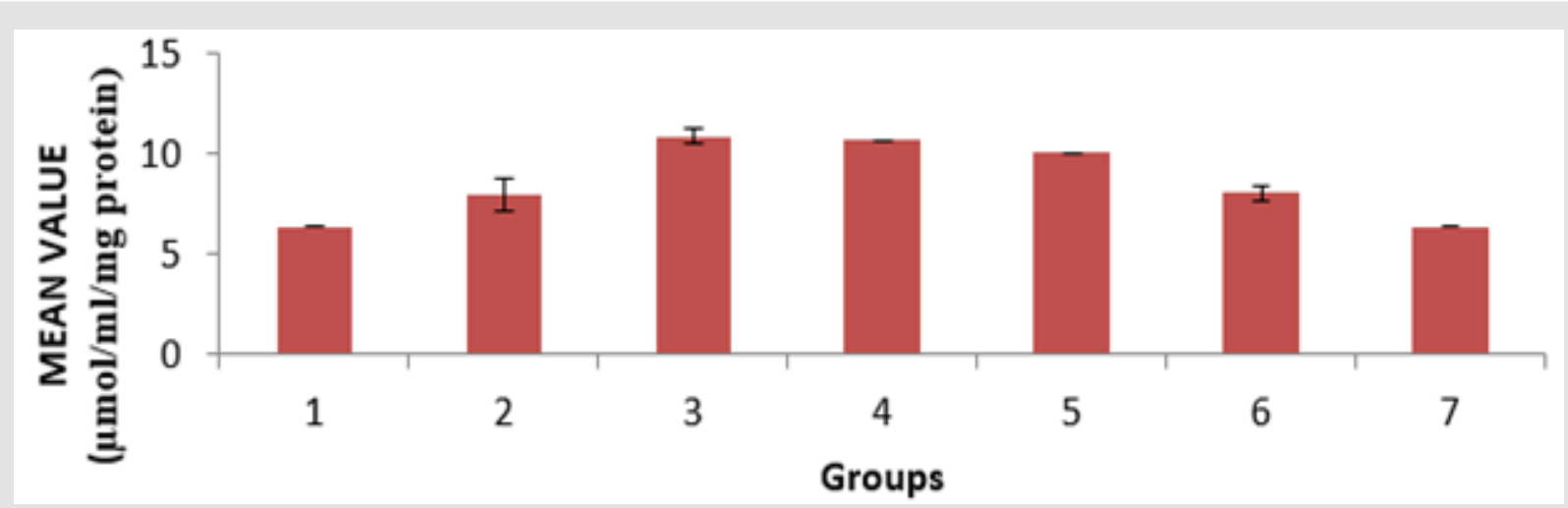

Figure 8: Superoxide dismutase (SOD) activity in the lungs of the experimental animals. Values were expressed as mean of three determinations \pm SEM. Differences were considered significant at $p<0.05$.
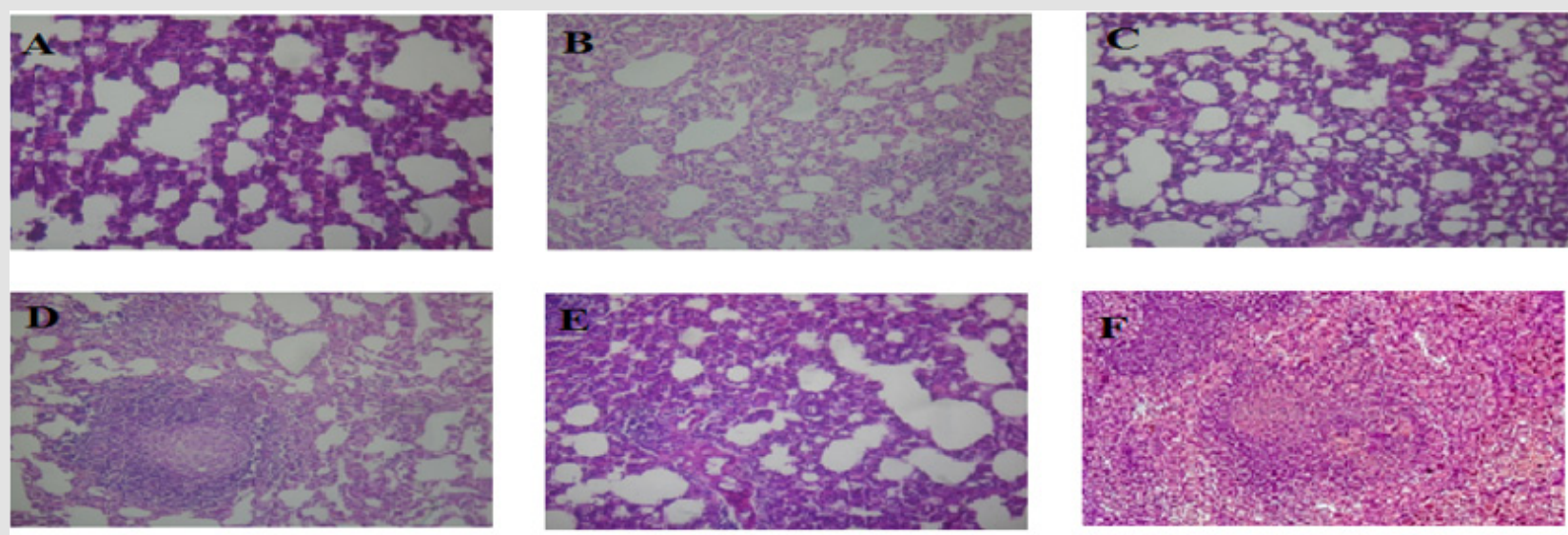

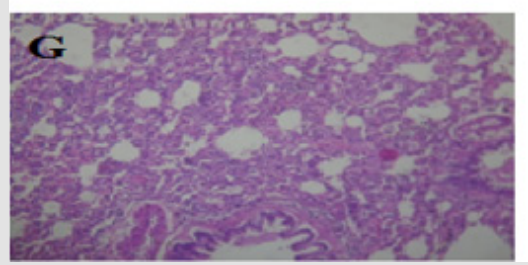

Plate 1: Histopathology of the lungs of the experimental rats.
A. (Coconut oil in high concentration at $0.4 \mathrm{ml} / \mathrm{kgb} . \mathrm{w}$ ),
B. (Coconut water in high concentration at $0.4 \mathrm{ml} / \mathrm{kg}$ ),
C. (Indapamine tablet at $0.2 \mathrm{ml} / \mathrm{kgb} . \mathrm{w}$ ),
D. (Coconut water in low concentration at $0.2 \mathrm{ml} / \mathrm{kgb} . \mathrm{w}$ ),
E. (Coconut oil in low concentration at $0.2 \mathrm{ml} / \mathrm{kgb} . \mathrm{w}$ ),
F. (No exposure to petrol (PMS) vapour and no treatment) and
G. (Exposed to petrol (PMS) vapour but not treated). Magnification: X400.

This present study was carried out to examine the mitigating effect of coconut oil and coconut water on the toxic effects of PMS inhalation. The frequent use of PMS especially in towns and cities for several domestic purposes makes it hard for individuals not to meet it. There is limited information on the use of medicinal plants in improving the health of people who are victims of the effect of PMS inhalation. The average uptake of inhalation exposure per day, of all the rats exposed to PMS vapour is represented in Table 2. The average uptake of inhalation exposure was not constant. The total average uptake of inhalation of exposure is $30 \pm 6.84 \mathrm{mg} / \mathrm{kgb} . \mathrm{w} /$ day. Coconut oil and coconut water have been known to have antioxidant and anti-inflammatory properties Cocoinfo International [11]. Coconut has been used to cure many illnesses and diseases and this is due to the biologically active compounds it possesses that act as anti-inflammatory and antioxidants (Table 1). 
Table 1: Treatment Schedule $(n=5)$.

\begin{tabular}{|c|c|}
\hline Group & Treatment \\
\hline 1 & $\begin{array}{r}\text { Coconut oil in high concentration of } 0.4 \mathrm{ml} / \mathrm{kgb} . w \\
\text { was administered orally. }\end{array}$ \\
\hline 2 & $\begin{array}{r}\text { Coconut water in high concentration of } 0.4 \mathrm{ml} / \\
\text { kgb.w was administered orally. }\end{array}$ \\
\hline 3 & $\begin{array}{r}\text { Indapamine tablet at } 0.2 \mathrm{ml} / \mathrm{kgb.w} \text { was } \\
\text { administered orally. }\end{array}$ \\
\hline 4 & $\begin{array}{r}\text { Coconut water in low concentration of } 0.2 \mathrm{ml} / \\
\text { kgb.w was administered orally. }\end{array}$ \\
\hline 5 & $\begin{array}{r}\text { Coconut oil in low concentration of } 0.2 \mathrm{ml} / \mathrm{kgb} . \mathrm{w} \\
\text { was administered orally. }\end{array}$ \\
\hline 6 (Negative control) & No exposure to PMS vapour and no treatment \\
\hline 7 (Positive control) & Exposed to PMS vapour but not treated \\
\hline
\end{tabular}

Table 2: Average Uptake of Inhalation Exposure per day for all exposed rats.

\begin{tabular}{|c|c|}
\hline Day & EHE (inha) $(\mathbf{m g} / \mathbf{k g} /$ day) \\
\hline 1 & $23.89 \pm 1.61$ \\
\hline 2 & $21.23 \pm 1.42$ \\
\hline 3 & $23.89 \pm 1.61$ \\
\hline 4 & $31.85 \pm 2.14$ \\
\hline 5 & $29.19 \pm 1.96$ \\
\hline 6 & $47.76 \pm 3.21$ \\
\hline 7 & $23.89 \pm 1.61$ \\
\hline 8 & $29.19 \pm 1.96$ \\
\hline 9 & $34.51 \pm 2.32$ \\
\hline 10 & $26.53 \pm 1.78$ \\
\hline 11 & $29.19 \pm 1.96$ \\
\hline 12 & $31.85 \pm 2.14$ \\
\hline 13 & $37.16 \pm 2.50$ \\
\hline 14 & $26.53 \pm 1.78$ \\
\hline
\end{tabular}

Note: *The average uptake of inhalation exposure for 14 days is not constant. The total average uptake of inhalation exposure is $30 \pm 6.84 \mathrm{mg} / \mathrm{kg} /$ day.

In this present study, it was observed that the exposure to PMS vapour in all 6 test groups resulted in a significant $(\mathrm{p}<0.05)$ increase of triacylglycerol (TAG), cholesterol (Chol), low density lipoprotein (LDL) level and decrease high density lipoprotein levels; elevation in malondialdehyde (MDA) level, a decrease in the level of reduced glutathione (GSH), activities of catalase (CAT), and superoxide dismutase (SOD). Exposure to PMS vapour significantly $(p<0.05)$ reduced the activity of SOD, GSH and CAT in the test animals when compared with the negative control. Similarly [12] observed a significant $(p<0.05)$ decrease in the antioxidant enzymes of experimental animals on exposure to PMS vapour. In this present study, the level of MDA significantly $(p<0.05)$ increased in the positive control when compared to the negative control. This is in agreement with previous studies that affirmed that exposure to petroleum products including PMS leads to increased MDA in rats and humans [13-15]. A significant $(p<0.05)$ increase in the MDA level of the positive control, compared with the other groups that were exposed to PMS vapour and treated showed that treatment with coconut oil and water may have reduced the abnormal generation of reactive oxygen species.

Lipid peroxidation results from the release of free radicals that can cause tissue damage by reacting with polyunsaturated fatty acids in cellular membranes to form malondialdehyde (MDA) [15]. Volatile hydrocarbons primarily get absorbed into blood via respiratory tract, leading to toxic effect on the lungs [16]. Several reports have shown that inverse relationship exists between lipid peroxidation and glutathione activities during stress [15]. Reactive oxygen species (ROS) are generated from molecular oxygen and nitrogen through Electron Transport Chain, cytochrome P450, and other cellular and sub-cellular functions [17]. The ROS which includes the superoxide radical $\left(\bullet_{2}\right)$, hydrogen peroxide $\left(\mathrm{H}_{2} \mathrm{O}_{2}\right)$ and hydroxyl radical $\left(\bullet \mathrm{OH}^{-}\right)$affect mainly lipids, proteins, carbohydrates and nucleic acid [18]. In most cases, the abnormal generation of reactive oxygen species, which results in significant damage to cell structure, is considered an important signal of oxidative damage [19]. Oxidative stress occurs when the presence of ROS is in excess of the available antioxidant buffering capacity [20]. The depletion of antioxidant enzymes predisposes the cell to the toxic actions of xenobiotics which could lead to cell injury or death. Hence, daily exposure to PMS vapour has the potential to produce oxidative stress and reduce antioxidant level.

There was a significant $(\mathrm{p}<0.05)$ decrease in the SOD activity of the positive control group when compared with the negative control. A slight elevation in the SOD activity of the groups exposed to PMS vapour may be as a result of treatment with coconut oil and coconut water. There was a reduction in the GSH level in group $1,2,4$ and the positive control when compared with the negative control, consequent to metabolism of agents in the PMS vapour which could contribute to the generation of reactive oxygen species. [21] affirmed that GSH level decreases on exposure to PMS vapour in untreated group when compared with the negative control. The CAT activity significantly $(\mathrm{p}<0.05)$ reduced in group 1,3 , and positive group compared to the negative group. A slight elevation in the CAT activity of group 2, 4 and 5 may be as a result of treatment with coconut oil and coconut water. Superoxide dismutase (SOD), reduced glutathione (GSH), and catalase (CAT) are endogenous antioxidant enzymes that act as free-radical scavengers and hence prevent and repair damage done by reactive oxygen species [22]. Antioxidant enzymes have been reported to play major primary antioxidant defence roles in catalyzing the dismutation of superoxide radical $\left(\bullet \mathrm{O}_{2}^{-}\right)$to $\mathrm{H}_{2} \mathrm{O}_{2}$ and decomposition of $\mathrm{H}_{2} \mathrm{O}_{2}$ to $\mathrm{H}_{2} \mathrm{O}$, respectively $[23,24]$. Glutathione protects cells from the free radicals produced through oxidation, while catalase catalyzes the decomposition of hydrogen peroxide to water and oxygen [23,25].

There was a significant $(p<0.05)$ increase in the levels of TAG and Chol in the groups exposed to PMS vapour. The significant ( $p$ 
$<0.05$ ) increase in TAG and Chol observed is an indication that inhalation on exposure to petrol vapour affects lipid metabolism. On one hand, lipid metabolism is affected once there is liver damage since the disturbance of cell membrane integrity is likely to cause some membrane lipids to be released into circulation; while on the other hand, it causes the tissue to compromise its effectiveness in regulating lipid metabolism [14]. There was a significant $(p<0.05)$ increase in the LDL levels of groups 2,3 , and positive control when compared with the negative control and a significant $(p<0.05)$ decrease in the HDL of groups 1, 3, 4, 5 and the positive control, when compared with the negative control. In the histology study of the lungs, inflammation was observed in the groups exposed to PMS vapour. No significant changes were observed in the lungs of the negative control. The histology study of group 1 which was exposed to PMS vapour and treated with coconut oil at $0.4 \mathrm{ml} / \mathrm{kgb} . \mathrm{w}$ showed alveolar air spaces with mild infiltration of surrounding interstitium by inflammatory cells in the lungs, indicating mild pulmonary inflammation.

[26] investigated the hypothesis that exposure of healthy volunteers to concentrated particles is associated with an influx of inflammatory cells into the lower respiratory tract and concluded that ambient air particles are capable of inducing a mild inflammation in the lower respiratory tract. The increase in the number of inflammatory cells has been reported as alveolitis, which refers to the cell types that are most abundant [26]. Pneumonitis is a general term that refers to the inflammation of lung tissue and is caused by irritants. The histology study of group 2, which was exposed to PMS vapour and treated with coconut water of $0.4 \mathrm{ml} / \mathrm{kg}$, showed reduction in alveolar air spaces with moderate infiltration of surrounding interstitium by inflammatory cells in the lungs. The histology study of group 3, which was exposed to PMS vapour and treated with $2 \mathrm{ml}$ indapamine showed the lungs alveolar air spaces with mild infiltration of surrounding interstitium by inflammatory cells in the lungs. Thus, indicating mild pulmonary inflammation. This showed that indapamine $2.5 \mathrm{mg}$, a diuretic pill had little significance on the effect of PMS.

The histology study of group 4, which was exposed to PMS vapour and treated with coconut water at $0.2 \mathrm{ml} / \mathrm{kgb} . \mathrm{w}$ showed the lungs alveolar air spaces, with infiltration of surrounding interstitium by aggregates of inflammatory cells forming granulomas. Thus, indicating granulomatous pulmonary inflammation. This showed that coconut water in low concentration had little or no significant effect of PMS vapour on the lungs of male albino rats. The histology study of group 5, which was exposed to PMS vapour and treated with coconut oil at $0.2 \mathrm{ml} / \mathrm{kgb} . \mathrm{w}$ concentration showed a reduction in alveolar air spaces with moderate infiltration of surrounding interstitium by inflammatory cells of the lungs. Thus, indicating moderate pulmonary inflammation. This showed that coconut oil in low concentration had little significance on the effect of PMS vapour on the lungs of male albino rats.

\section{Conclusion}

The results obtained show that exposure to PMS is toxic to the lungs and could cause inflammation. It also shows that exposure to petrol vapour increases oxidative stress and reduces the activities of antioxidant enzymes. Coconut oil and its water have antioxidant and anti-inflammatory properties that may mitigate the effect of PMS vapour in the body.

\section{References}

1. (2009) European Public Health Alliance. Air, water pollution and health effects.

2. Caprino L, Togna GI (1998) Potential health effects of gasoline and its constituents: a review of current literature (1990-1997) on toxicological data. Environmental Health Perspective 106(3): 115-125.

3. (2014) Office of Environmental Health Hazard Assessment (OEHHA). Fuels and your health. facts sheet of the california environmental protection agency's Office of Environmental Health Hazard Assessment (OEHHA) and The American Lung Association of California (ALAC). Sacramento, California.

4. Rothman N, Li GL, Dosemeci M, Bechtold WE, Marti GE, et al. (1996) Haematotoxicity among chinese workers heavily exposed to benzene. American Journal of Industrial Medicine 29(3): 236-246.

5. Bruce D (2009) Coconut oil miracle. Adventure works press, Philippines.

6. Gidez LI, Miller GJ, Burstein M, Slagle S (1982) Separation and quantification of subclasses of human high density lipopoproteins by a simple precipitation procedure. Journal of Lipid Research 23(8): 1206-1223.

7. Sun M, Zigma S (1978) An Improved Spectrophotometric Assay of Superoxide Dismutase Based on Ephinephrine Antioxidation. Annals of Biochemistry 12: 81-89.

8. Sinha AK (1972) Colorimetric assay of catalase. Analytical Biochemistry 60: 47 .

9. Sedlak J, Lindsay RH (1968) Estimation of total, protein-bound, and non-protein sulfhydryl groups in tissue with ellman's reagent. Annals of Biochemistry 25(1): 192-205.

10. Buege JA, Aust SD (1978) Microsomal lipid peroxidation. Methods of Enzymology 18: 302-310.

11. (2004) Cocoinfo International, Coconut water and its medicinal properties. Asian and Pacific Coconut Community Journal 11(1): 25-28.

12. Owagboriaye FO, Dedeke GA, Aladesida AA, Bamidele JA, Olooto WE (2016) Assessment of the effect of gasoline fume on antioxidant status and lipid peroxidation in albino rats. Journal of King Saud University 9: 10-15.

13. Bokolo B, Ligha AE (2013) Antioxidative effect of zinc on gasoline. Research Journal of Pharmaceuticals, Biological and Chemical Sciences 4(3): 45-52.

14. Uboh FE, Akpanabiatu MI, Eyong EU, Ebong PE, Eka 00 (2005) Evaluation of toxicological implications of inhalation exposure to kerosene fumes and petrol fumes in rats. Acta Biologica Szegediensis 30: 19-22.

15. Odewabi AO, Ogundahunsi OA, Oyalowo M (2014) Effect of exposure to petroleum fumes on plasma antioxidant defense system in petrol attendants. British Journal of Pharmacology and Toxicology 5: 83-87.

16. Azeez OM, Akhigbe RE, Anigbogu CN (2012) Exposure to petroleum hydrocarbon: implications in lung lipid peroxidation and antioxidant defense system in rat. Toxicology International 19(3): 306-309.

17. Noori S (2012) An overview of oxidative stress and antioxidant defensive system. open access. Scientific Reports 6: 1-9.

18. Damien C, Chantal VH, Pirouz S, Zerimech FH, Laurence J, et al. (2004) Cellular impact of metal trace elements in terricolous lichen diploschistes 
muscorum. Identification of oxidative stress biomarkers. Water Air and Soil Pollution 152(1-4): 55-69.

19. Barzilai A, Yamamoto KI (2004) DNA damage responses to oxidative stress. DNA Repair 3: 1109-1115.

20. Adly AA (2010) Oxidative stress and disease: an updated review. Research Journal Immunology 3(2): 129-145.

21. Muhammad GY, Frederick O (2013) Effect of exhaust fumes on glutathione s-transferase enzymes in the lung of rats supplemented with natural products. British Journal of Pharmacology and Toxicology 3: 29-35.

22. Wu JQ, Kosten TR, Zhang XY (2013) Free radicals, antioxidant defense systems, and schizophrenia. Progress in Neuropsychopharmacology and Biological Psychiatry 33: 200-206.

\section{ISSN: 2574-1241}

DOI: $10.26717 /$ BJSTR.2020.25.004155

Onifade OF. Biomed J Sci \& Tech Res

This work is licensed under Creative Commons Attribution 4.0 License

Submission Link: https://biomedres.us/submit-manuscript.php
23. Chelikani P, Fita I, Loewen PC (2004) Diversity of Structures and Properties Among Catalases. Cellular and Molecular Life Science 61(2): 192-208.

24. Goodsell DS (2010) Catalase molecule of the month. Methods of Molecular Biology 648: 269-277.

25. Pastore A, Piemonte F, Locatelli M, Russo AL, Gaeta LM, et al. (2003) Determination of blood total, reduced, and oxidized glutathione in pediatric subjects. Clinical Chemistry 47(8): 1467-1469.

26. Mercer RR, Russell ML, Crapo JD (1994) Alveolar septal structure in different species. Journal of Applied Physiology 115: 1060-1066.

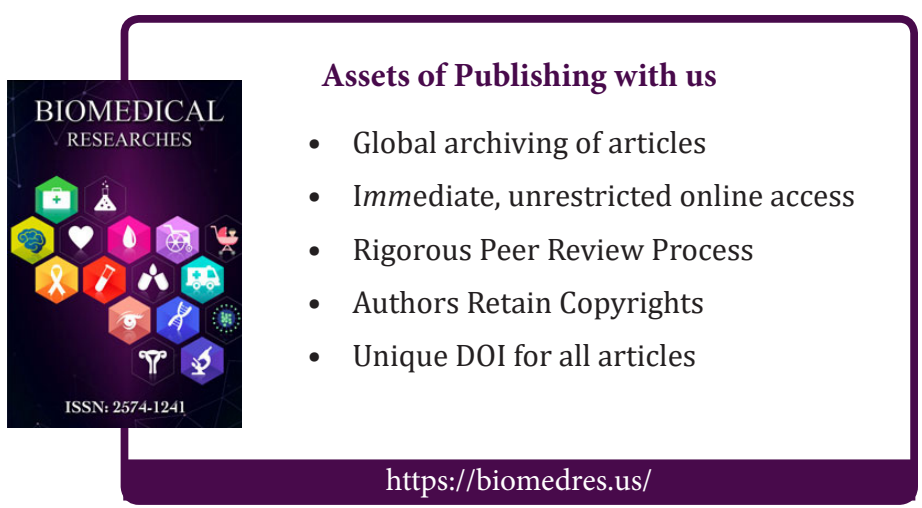

